\title{
POSTPRINT
}

\section{Editorial: Instructions in driving lessons}

\section{Arnulf Deppermann (1)}

\author{
Mannheim, Germany
}

Driving lessons count among the most important pedagogical settings in contemporary society. In $2012,1.5 \mathrm{~m}$ practical exams for a driving licence were held in Germany (Spiegel online, 2013), 949,000 in the UK in 2014 (gov.uk, 2015), 140,000 in Switzerland (asa, 2015). About 30\% of the applicants fail the practical exam. In many countries (like Germany, Ireland, Switzerland, some parts of Canada and the US), it is mandatory to take driving lessons in order to be able to apply for a driving licence. Although a major part of the population in contemporary societies thus participates in driving lessons at some point in their lives, there is virtually no research on this pervasive type of social interaction. It is only very recently that linguists have started to publish first studies (Broth, Levin, \& Cromdal, 2017; De Stefani \& Gazin, 2014; Deppermann, 2015; Gazin, 2015). The neglect of driving lessons as a topic of research in language and communication is mirrored by the fact that professional training of driving instructors does not involve training in linguistic and communicative skills concerning, for example, the design of instructions, giving feedback, or explaining the rationale of certain obligatory driving practices. Although they offer a rich field of interesting linguistic, communicative and pedagogical phenomena, driving lessons thus have not been a topic in applied linguistics yet.

This Special Issue of InJAL is the first volume ever which is specifically devoted to linguistic and interactional research on driving lessons. It gathers papers which all focus on the ways in which instructions are produced in driving lessons in five different languages (French, Finnish, German, Italian, Swedish). The studies show how the design of instructions in this setting is informed by the specific conditions of driving, which differ importantly from other pedagogical settings. The authors identify strategies which instructors use to deal the specific tasks and contingencies emerging in this type of interaction. Since tasks and patterns of interaction studied in the six articles of this special issue are neatly comparable, the articles also offer insights into the language-specifity of instructional practices in driving lessons.

The articles in this volume all take a multimodal conversation analytic and interactional linguistic approach. Conversation Analysis studies the organization of action in social interaction (Schegloff, 2007). It focuses on the ways in which participants design turns at talk and jointly produce social structures in sequences of initiative and responsive actions. Basic orders of interaction which are studied in Conversation Analysis therefore are turn-construction, turntaking, and sequence organization (see Sidnell \& Stivers, 2013). Sequence organization most basically is shaped by adjacency pairs, i.e. first actions (e.g. questions, requests) making a certain type of second actions (e.g. answers, compliant actions) conditionally relevant (Schegloff, 2007). Instructions are a kind of first actions and make compliance conditionally relevant. Interactional Linguistics builds on Conversation Analysis, adding an interest in how linguistic resources are used to implement certain actions in talk. Thus the precise design of turn-construction and the ways in which actions are constructed linguistically is in focus. Interactional Linguistics studies how language is tailored to the interactional conditions of its use (e.g. spatial conditions, prior turns) and how it is flexibly used to perform actions according to participants' situated concerns (Couper-Kuhlen \& Selting, 2008). More recently, researchers in Conversation Analysis and Interactional Linguistics have turned to the study of multimodal interaction (e.g. Deppermann, 2013; Mondada, 2016). In addition to the focus on talk and its sequential organization, Multimodal Interaction Analysis widens the scope to include the simultaneity of bodily action, the coordination of talk and other 
multimodal resources and to capture how action in interaction is organized in complex multimodal gestalts (Mondada, 2014a). These include the methodically coordinated use of talk, gaze, gestures, facial expression, the manipulation of objects and other movements in space in order to get the interactional business done. Multimodal Interaction Analysis rests on video-taped recordings of naturally occurring interactions, which are transcribed according to transcription conventions which cover both talk and participants' multimodal conduct.

The topic of this Special Issue is instruction. 'Instruction' can be understood in at least three different ways (see Lindwall, Lymer, \& Greiffenhagen, 2015; see also Mondada, 2014b): a written guideline which describes a series of steps of actions to take in order to perform a task or produce some object (like a recipe or a construction manual) (a); a pedagogical activity which is intended to teach new knowledge to a novice (b); a request which informs the addressee what to do and how to do it (c). Instructions in driving school belong to the two latter varieties: They are oral activities by which an expert (the instructor) trains a novice (the student) to perform some action in the correct way. This action may be due at the time or later, on the next relevant occasion. Instruction may additionally involve explanations or descriptions which account for reasons, side conditions, consequences, etc. which impinge on the design of correct (and also problematic) actions.

Instructions in driving schools are produced in the context of interaction sequences whose basic architecture resembles those of other pedagogic interaction types. Most importantly, they are basically organized as I-R-E sequences (initiative-response-evaluation, see Mehan, 1979; Sinclair \& Coulthard, 1975), which are well-known from research on classroom interaction (cf. Koole, 2015). Instructions always inhabit the "l"-slot, whereas instructed actions fill the "R"-slot. The pedagogical specialization of this sequential pattern can not only be seen by the fact that its turn-types are role-specific, with instructors always initiating sequences and students producing requested responses. In contrast to most everyday adjacency pairs which involve an initiative-response sequence (like question-answer, request-compliance, offer-acceptance/denial), there is also an evaluative sequence-closing third action produced by the instructor, who assesses the success and correctness of the student's response.

While the basic I-R-E-structure corresponds to other pedagogical settings, driving lessons differ from them in a number of other aspects which also inform linguistic choices:

- Two-person participation framework: in contrast to the one-to-many participation framework of classroom interaction, driving lessons are dyadic interactions. Therefore, the instructor can exclusively focus on the individual student and adapt their instructional activities accordingly. The student, in turn, is continuously required to respond to instructions and display their understanding. By this, the instructor can systematically monitor the learningprocess of the individual student and design actions with respect to the specific competencies and problems of their specific addressee. Changes in the linguistic and gestural design of instructions over time therefore are closely tied to the accumulation of shared knowledge over the common interactional history and to the learning process of the student: instructions become increasingly economical, that is, more elliptic, exhibiting a leaner argument structure, using indexical instead of full lexical phrases and requiring less understanding checks and displays from the student (Deppermann, in press).

- Mobility: driving involves that the car is moving through different spatial configurations. Since other traffic participants are also on the move, these conditions are constantly changing, often in rather unforeseen ways. Therefore, there is a need for permanent monitoring of the current traffic condition, for the anticipation of next actions by other traffic participants and for timely responses to (sudden) changes in the environment. These conditions entail that responses to instructions are precision-timed with respect to the time courses of traffic and that students' responses often have to be immediate and well-coordinated with other traffic events.

- Multimodality: Driving skills themselves are essentially non-verbal - although they include verbal knowledge as well, for example, the understanding of technical terms like $b$-column, biting point, or blind spot and knowledge of the code of traffic. Because of the multimodal nature of the skills to be learnt, a good deal of instructional practice also involves non-verbal elements, such as demonstrating in which directions the student should look in which order when reverse parking a car, how s/he has to check the different mirrors of the car when turning 
at an intersection or various sorts of gestural displays which, for example, are used to display how the clutch is to be operated (Broth et al., 2017). Deppermann (2016) has shown how gestural enactment of procedures is a constitutive part of definitions of new technical terms for car controls and their use in these settings. The student's non-verbal driving performance is not only the ultimate goal of the pedagogical activity. In contrast to many classroom settings, student's understanding and their competence during task-performance become immediately and directly visible for the instructor. Instructors are thus provided with rather straightforward in-situ criteria by which they can assess the student's progress of learning.

- Side-by-side position: since instructor and student are positioned side-by-side (Kendon, 1990), they both share basically the same perspective on the road. However, this line-up sometimes creates problems for the coordination of joint attention, because mutual gaze is not possible during driving and it is therefore hard to monitor both the road and the orientation of the partner's visual attention at the same time. This can create difficulty for the use of spatial deictics, which may not be resolved properly by the addressee, and for gestural practices, which may not be properly perceived during driving. The side-by-side position also can cause problems if actions and referents in the back are to be attended to, which makes more complex ways of describing spatial constellations and driving directions necessary.

- Multi-activity: instructions during driving are inevitably part of a multi-activity framework (cf. Haddington, Keisanen, Mondada, \& Nevile, 2014): The student has to listen to the instruction and plan a response while performing current driving actions and having to monitor relevant traffic conditions (other participants, traffic lights, road signs, etc.). This multi-activity framework creates difficult conditions and is likely to cause failures of action, attention and understanding on the student's part. This is particularly the case in the first lessons, when no routines are established yet. It also puts constraints on successful instructional practices, because instructors have to coordinate their instructions with other contingencies of driving and monitoring in a temporally finegrained manner and they have to wait for the right moments in order to claim the student's attention. This is especially important for first instructions and accounts for actions, which exhibit a more complex linguistic design and which therefore require undivided attention from the student. In addition, a major part of successful learning just consists of being able to smoothly and routinely coordinate multiple driving requirements at the same time in patterns of multi-activity, including to be able to listen and talk while driving (cf. Mondada, 2012).

In instruction sequences in driving school, different types of instructions are produced. Navigational instructions formulate directions (turn left at the next intersection, we head for the motorway, we take the first parking box, etc.), car control instructions concern the handling of the car (engage the clutch, reduce speed, activate the indicator, etc; see De Stefani \& Gazin, 2014 for this distinction). There is a third variety, monitoring instructions, which concern the use of the mirrors and directions where to look (watch who is coming from the right, look back, look far ahead, etc.). Navigational instructions open up larger instruction sequences by setting a complex task to be fulfilled. Within these sequences, car control and monitoring instructions are used as corrective instructions (Deppermann, 2015). Corrective instructions respond to students' failures to carry out the navigational instruction in the proper way, namely, they concern the individual steps of actions, their order, their timing and their coordination with the emerging spatio-temporal traffic situation. Actions like speeding up, monitoring overtaking traffic in the mirror, checking the blind spot, changing gears, etc., their precise timing, their order and their relationship to what other cars are found to be doing may become the object of corrective instruction when the student has been instructed to change lanes. Navigational instructions especially thus, do not just call for a simple response. They make a whole series of coordinated actions conditionally relevant until task-performance is complete. The student is expected to select and produce these actions self-initiatedly. Like in other settings of complex instructed activities, following an instruction in driving school thus is a highly reflexive and indexical activity (Amerine \& Bilmes, 1988; Garfinkel, 2002): The way the instruction is complied with indexes a specific understanding of the instruction and of the ways in which the task is to be solved given the current circumstances. This in turn may be negotiable and subject to corrective instructions (see also Ekström \& Lindwall, 2014; Lindwall \& Ekström, 2012). 
Building on these findings, the papers in this Special Issue focus on different aspects of the linguistic design and the interactional production and treatment of instructions in driving lessons. They also yield insights into the different ways in which linguistic structures are used to produce instructions in different languages. By this, they contribute to a better understanding of the language-specific resources of action-formation.

In "Formulating direction. Navigational instructions in driving lessons," Elwys De Stefani analyses when navigational instructions in Italian are produced with respect to an ongoing course of talk and driving action. He reveals a highly recurrent systematics according to which linguistic resources are used to build turns which include place references and directional references. De Stefani also analyses how the verbal and the gestural design of navigational instructions is tailored to different levels of the student's competence and thus reflects the instructor's understanding of the student's learning process.

Arnulf Deppermann studies "Instruction practices in German driving lessons. Differential uses of declaratives and imperatives." While declaratives are used for first instructions, task-setting and post-trial discussions, imperatives overwhelmingly correct ongoing actions of students or respond to failures to produce expected actions. While declaratives exhibit complex argument structures, imperatives come with a lean argument structure. They index that the requested action is taken to be already known by the student, that it can be performed unproblematically and that it is immediately, and sometimes even urgently, due. The two instruction formats thus can be seen to be differently used depending on learning history and spatiotemporal contingencies.

Daniel Björklund studies the ways in which a specific skill is instructed: "Drilling the mirror routine: from nonsituated looking to mobile practice in driver training." Using data from Sweden, he traces how a routine series of actions to be performed when turning into another street at an intersection is instructed in consecutive trials, starting with schematic graphic representations and later in live traffic. Björklund shows how instructions change from desituated explanation to instruction while driving, which additionally has to take local spatial structures, the presence of other road users and concurrent driving operations of the student into account.

The instruction of another specific skill is the topic of the paper by Mathias Broth, Jacob Cromdal and Lena Levin: "Showing where you're going. Instructing the accountable use of the indicator in live traffic." Also using data from Swedish driving lessons, they analyse how instructors explain to students how to make the car's behaviour accountable to other road users. Instructions for using the indicator take into account its precise timing as part of more encompassing turning procedures. The use of the indicator is motivated as being a means of communication, which allows others to anticipate a car's movement in space. This is crucial for their possibilities to coordinate themselves with other road users. The authors also discuss the temporal relationship of more elaborate accounts to the requirements of the process of driving.

Mirka Rauniomaa deals with a non-canonical way of formulating instructions: "Noticings with instructional implications in post-licence driver training." She discusses how noticings by the instructor that concern current traffic events or habitual practices of the student are used to prompt the driver to adjust her driving. By producing noticings, the instructor displays his ongoing monitoring of the student's performance and his assessment of the driver's performance and he inferentially makes available his expectations regarding the driver's experience and competence.

The final contribution to this Special Issue is by Lorenza Mondada, who analyses driving lessons of a non-ordinary kind: "Driving instruction at high speed on a race circuit: Issues in action formation and sequence organization." In this setting, drivers who are already highly competent are assisted by a coach to improve their performance and speed in race-car driving. The author reveals the basic instructional practices in this specific setting, their extremely economical linguistic formats and how these instructions are organized in sequences and as series of sequences. The paper shows how precision-timed performance, routines and sequence organization are intertwined in this setting of professional instruction.

\section{ORCID}

Arnulf Deppermann (D) http://orcid.org/0000-0001-7575-8236

\section{REFERENCES}

Amerine, R., \& Bilmes, J. (1988). Following instructions. Human Studies, 11(2), 327-339. 
asa (2015), Retrieved February 7, 2018 from http://www.fahrlehrerverband.ch/wp-content/uploads/2015/03/StatPruef 2014_de.pdf

Broth, M., Levin, L., \& Cromdal, J. (2017). Starting out as a driver: Progression in instructed pedal work. In Å. Mäkitalo, P. Linell, \& R. Säljö (Eds.), Memory practices and learning. Interactional, institutional and sociocultural perspectives (pp. 113-142). Charlotte, NC: IAP Publishers.

Couper-Kuhlen, E., \& Selting, M. (2008). Interactional linguistics. Cambridge: Cambridge University Press.

De Stefani, E., \& Gazin, A. (2014). Instructional sequences in driving lessons: Mobile participants and the temporal and sequential organization of actions. Journal of Pragmatics, 65, 63-79.

Deppermann, A. (Ed.) (2013). Conversation analytic studies of multimodal interaction. Journal of Pragmatics, 46(1), 1-172.

Deppermann, A. (2015). When recipient design fails: Egocentric turn-design of instructions in driving school lessons leading to breakdowns of intersubjectivity. Gesprächsforschung, 16(1), 63-101. Retrieved 7 February 2018 from http://www. gespraechsforschung-ozs.de/fileadmin/dateien/heft2015/ga-deppermann.pdf

Deppermann, A. (2016). La définition comme action multimodale et contexte-sensitive: Définir pour instruire dans l'auto-école. Langages, 204(4), 83-101.

Deppermann, A. (in press). Changes in turn design over interactional histories - the case of instructions in driving school lessons. In A. Deppermann, \& J. Streeck (Eds.), Temporalities and modalities. Amsterdam: Benjamins.

Ekström, A., \& Lindwall, O. (2014). To follow the materials: The detection, diagnosis and correction of mistakes in craft education. In M. Nevile, P. Haddington, T. Heinemann, \& M. Rauniomaa (Eds.), Interacting with objects: Language, materiality, and social activity (pp. 227-247). Amsterdam: John Benjamin.

Garfinkel, H. (2002). Instructions and instructed actions. In H. Garfinkel (Ed.), Ethomethodology's Program (pp. 197-218). Oxford: Rowman \& Littlefield.

Gazin, A.-D. (2015) Instructional sequences in the moving car. A conversation analytic approach to multimodal interaction in driving lessons. (PhD thesis), Bern.

gov.uk (2015), Number of new driving licence applications in the last three years. Retrieved 7 February 2018 from https://www. gov.uk/government/publications/number-of-new-driving-licence-applications-in-the-last-three-years

Haddington, P., Keisanen, T., Mondada, L., \& Nevile, M. (Eds.) (2014). Multiactivity in social interaction: Beyond multitasking. Amsterdam: Jahn Benjamins.

Kendon, A. (1990). Conducting interaction: Patterns of behavior in focused encounters. Cambridge: Cambridge University Press.

Koole, T. (2015). Classroom interaction. In K. Tracy (Ed.), International encyclopedia of language and social interaction. New York: Wiley-Blackwell. https://doi.org/10.1002/9781118611463.wbielsi092

Lindwall, O., \& Ekström, A. (2012). Instruction-in-interaction: The teaching and learning of a manual skill. Human Studies, 35(1), $27-49$.

Lindwall, O., Lymer, G., \& Greiffenhagen, C. (2015). The sequential analysis of instruction. In N. Markee (Ed.), The handbook of classroom discourse and interaction (pp. 142-157). Hoboken, NJ: Wiley.

Mehan, H. (1979). Learning lessons. Social organization in the classroom. New York: Harvard University Press.

Mondada, L. (2012). Talking and driving: Multiactivity in the car. Semiotica, 191(1/4), 223-256.

Mondada, L. (2014a). The local constitution of multimodal resources for social interaction. Journal of Pragmatics, 65, 137-156.

Mondada, L. (2014b). Instructions in the operating room: How the surgeon directs their assistant's hands. Discourse Studies, 16(2), 131-161.

Mondada, L. (2016). Challenges of multimodality: Language and the body in social interaction. Journal of SocioLinguistics, 20(3), 336-366.

Schegloff, E. A. (2007). Sequence organization in interaction. Cambridge: Cambridge University Press.

Sidnell, J., \& Stivers, T. (Eds.) (2013). Handbook of conversation analysis. New York: Wiley-Blackwell.

Sinclair, J. M., \& Coulthard, R. M. (1975). Towards an analysis of discourse: The English used by teachers and pupils. Oxford: Oxford University Press.

Spiegel online (2013). Zahl der Führerscheinprüfungen sinkt erneut. Retrieved 7 February 2018 from http://www.spiegel.de/ auto/aktuell/zahl-der-fuehrerscheinpruefungen-sinkt-erneut-a-929241.html

How to cite this article: Deppermann A. Editorial: Instructions in driving lessons. Int J App/ Linguist. 2018;1-5. https://doi.org/10.1111/ijal.12206 